\title{
VII. The chemical and geological history of the atmosphere
}

\author{
John Stevenson M.A. F.I.C.
}

To cite this article: John Stevenson M.A. F.I.C. (1905) VII. The chemical and geological history of the atmosphere, Philosophical Magazine Series 6, 9:49, 88-102, DOI: 10.1080/14786440509463258

To link to this article: http://dx.doi.org/10.1080/14786440509463258

册 Published online: 08 Jun 2010.

Submit your article to this journal $[\pi$

Џll Article views: 2

Q View related articles $₫$ 
or

$$
\frac{\mathrm{X} \cos \lambda}{d+\cos \alpha}+\frac{Y \cos \mu}{d+\cos \beta}+\frac{Z \cos v}{d+\cos \gamma}
$$

$=\left(\frac{n}{d \mathrm{D}_{3}-\Delta}\right)\left(\frac{d \mathrm{X}}{n_{1}+d}\left(l_{1} \mathrm{D}_{1}+m_{1} \mathrm{D}_{2}+n_{1} \mathrm{D}_{3}+\Delta\right)+\ldots+\ldots\right)=0$.

Hence the first part of the theorem follows as in $\S 1$. The second part is proved as in $\S 2$, if we notice that the projection of the intersection of any two planes passes through the projection of the intersection of the lines in which these two planes meet the plane ABC.

6. Similarly, the projection of the line of intersection of the zone $[U V W]$ with the plane $A^{\prime} B^{\prime} C^{\prime}$ is the line $\mathrm{U} \xi+\mathrm{V} \eta+\mathrm{W} \xi=0$, and the projection of the normal through 0 to the face $(u v w)$ passes through $\frac{\xi}{u}=\frac{\eta}{v}=\frac{\zeta}{w}$, where $(d+\cos x) \xi=\mathrm{X} a \cos \mathrm{AOA}^{\prime} \& \mathrm{c}$. ; the vertices of the triangle of reference being the projections of the poles of $\left(\begin{array}{ll}1 & 00\end{array}\right)$, $\left(\begin{array}{llll}0 & 1 & 0\end{array}\right),\left(\begin{array}{lll}0 & 0 & 1\end{array}\right)$.

7. The most interesting cases are those in which $d=0,1$, or $\infty$, corresponding to a gnomonic, stereographic, or orthogonal projection. It may be readily shown that the theorems still hold in these special cases.

2 Bryn Teg Terrace, Bangor, North Wales.

VII. The Chemical and Geological History of the Atmosphere. By John Stevenson, M.A., F.I.C.*

\section{III.}

Variations in the Amount of Atmospheric Carbonic Acid, with special reference to the subject of Geological Climate.

TN the two former articles of this series (Phil. Mag. 1 Sept. 1900, p. 312; Oct. 1900, p. 399, and Oct. 1902, p. 435), in which questions relating to the history of free oxygen and the composition and extent of the primitive atmosphere were discussed, we concluded that the atmosphere was almost certainly many times more extensive in very primitive times than it is now; that it probably contained no free oxygen; that it most probably contained very large quantities of carbonic acid; and that it possibly may have contained large quantities of hydrogen and hydrocarbon gases either in addition to, or instead of, the carbonic acid gas.

Assuming that the latter were the principal gases originally

* Communicated by the Author. 
present, we saw that they would be converted into water and carbonic acid through the agency of vegetation. There is even a possibility that they may have been directly absorbed by ancient forms of vegetation, and in the subsequent heating by volcanic action of the vegetable remains in presence of rocks containing oxide of iron, carbonic oxide, carbonic acid and water would be produced. Carbonic acid, whether produced in this way or present from the first in the atmosphere, would also be absorbed by vegetation, this process of absorption being accompanied by the decomposition of the carbonic acid and the production of free oxygen, though it should be noted that there would not be permanent free oxygen in the atmosphere as long as free hydrogen existed. The free oxygen produced from carbonic acid by vegetable growth being in the nascent condition, wonld immediately combine with the hydrogen fresent in the atmosphere producing water, as inferred from Dr. Phipson's experiment which was referred to in a previous article. It is possible, no doubt, that the hydrogen which disappeared in the course of the experiment was absorbed directly by the plant; but its oxidation by nascent oxygen seems a highly probable explanation of the effect observed; and in any case it is obvious that we conld not expect free oxygen and free hydrogen to exist long together in the atmosphere in considerable quantities. After all the tree hydrogen had disappeared, permanent free oxygen, i.e. free oxygen as a permanent constituent of the atmosphere, would begin to appear, and the quantity would gradually increase until it reached a limit determined principally by the amount of oxidizable matter within reach and the readiness of this oxidizable matter to combine with oxygen under prevailing conditions. On the other hand, the quantity of carbonic acid in the atmosphere would probably diminish steadily during the early geological epochs, until a certain limiting percentage determined by a variety of conditions was reached. Large quantities of carbonic acid are annually produced and added to the atmosphere through the operation of various agencies or reactions, and large quantities are removed or decomposed, principally through. the growth of vegetation and the weathering of rocks; that is to say, through the decomposition of silicates by carbonic acid and water, resulting in the formation of carbonates and free silica, or of rocks containing a higher proportion of silica than the original rocks. This latter process probably operated with very great effect in early geological epochs, when the proportion of carbonic acid in the atmosphere was greater than it is now; and we also infer that 
there was probably a long period during which the forces or agencies which removed carbonic acid from the atmosphere were stronger than those which produced or returned it.

However, it is quite possible that after a certain point was reached in this abstracting process, the amount of carbonic acid in the atmosphere may have become variable; that is to say, the quantity may have alternately increased and diminished according to the relative activity of the forces or reactions which produce or evolve carbonic acid, and the counteracting forces or reactions which decompose carbonic acid or otherwise remove it from the atmosphere.

The view that the amount of atmospheric carbonic acid varies or may vary within very wide limits is not a new one; at least the view that the percentage was at one tiem very. different from what it is now is by no means new. Hugh Miller and probably most of his contemporaries were of opinion that the amount of carbonic acid in the atmosphere at the beginning of the Carboniferous epoch was very much greater than it is now, the difference being represented roughly by the amount of coal deposited during and since that period, and therefore amounting to many times, possibly one hundred or even several hundred times, the amount of our present atmospheric carbonic acid. Probably, however, the view usually taken by the earlier geologists on the question was not so much that the amount of atmospheric carbonic acid varies from time to time, as simply that the amount was very much greater in very early times than it is now. That is not quite the view taken in the present article. We propose to give reasons in support of the view that the amonnt of carbonic acid in the atmosphere has varied very considerably by increasing at certain times as well as by decreasing at others, during a very large part of geologieal history-possibly enough in early epochs such as the Cambrian and Silurian, as well as in more recent times.

It is obvious that among the forces which produce or evolve carbonic acid a prominent place is occupied by volcanic action. It has long been known that carbonic acid is evolved from volcanoes and also from the ground in volcanic districts even where the volcanoes are no longer active. This volcanic or telluric carbonic acid (as it was called by Prof. Dittmar) is probably for the most part produced by the heating of rocks containing limestone or other carbonates along with sandstone (silica), or with rocks containing a high percentage of silica to such an extent that the carbonates are decomposed and silicates are produced (or silicates with a larger percentage of base than the original 
silicates are produced), the reaction in both cases being accompanied by the evolution of carbonic acid. Another way in which carbonic acid may be evolved throngh volcanic action, is by heating rocks containing oxide of iron in presence of coal or carbonaceous matter to such an extent that metallic iron is produced, and carbonic acid and carbonic oxide are evolved.

Now it is highly probable that throughout geological history, voleanic action has varied considerably in its degree of activity. At any rate, we know for a certainty that it has varied to a very great extent in special areas or localities; and it is quite probable that on the earth, taken as a whole, volcanic activity has varied very considerably in degree in different geological epochs. Even if the amount of volcanic action as inferred from the production of volcanic rocks and other heating effects should have been fairly constant on the earth as a whole, yet the amount of carbonic acid produced or evolved may have varied very considerably according to variations in the composition and distribution of the rocks subjected to heating. The question therefore naturally arises as to whether such variations may have taken place to such an extent as to affect materially the amount and percentage of atmospheric carbonic acid.

In order to approach this question, it is obviously necessary that we should ascertain with a sufficient degree of approximation (1) the amount of curbonic acid at present existing in the atmosphere; (2) the amount of carbonic acid annually produced or evolved into the atmosphere by the principal agencies which have this effect; (3) the amount which is annually decomposed or removed from the atmosphere by other agencies; (4) the possible and probable variations that take place in the degree of activity of these various agencies ; and (5) the methods in and extent to which these agencies react on ench other.

As regards the amount of carbonic acid in the atmosphere, this may be taken in round figures as $2 \cdot 2 \times 10^{12}$ tons (rather more than two million million tons). The most recent and reliable determinations of atmospheric carbonic acid give a figure considerably lower than those which formerly were accepted. Prof. Letts, of Belfast, investigated the whole subject very carefully a few years ago, and found that the average amount of carbonic acid in the air at Queen's College, Belfast, was only $2 \cdot 93$ volumes in 10,000 volumes of air, or 0.0293 per cent. by volume; and this tigure is more likely to be over than under the average for the whole earth, as the air of cities is richer in carbonic acid than ordinary sea and 
country air. Müntz and Aubin of Paris, who made or collected a large number of the most reliable determinations. made in various parts of the world, found that the average percentage of carbonic acid in the air of the Nortbern Henisphere (as calculated from the data supplied by the material collectedj was 0.0282 by volume, and that the average percentage in the Southern Hemisphere was 0.6272. The mean of these two percentages is $0.027 \overline{7}$, which may therefore be taken as the average for the atmosphere as a whole. This figure, when reduced to percentage by weight, becomes 0.0423 , carbonic acid gas being 1.528 times heavier than ordinary air. At this percentage the total quantity of carbonic acid in the atmosphere (the weight of which, as we have already seen, may be taken as $5200 \times 10^{12}$ tons) becomes $2 \cdot 2 \times 10^{12}$ tons, as stated above.

Of the various agencies which affect the amount of carbonic acid in the atmosphere, either by adding to or removing from it, probably the most important at the present. time are the growth of vegetation, on the one hand, and the oxidation of vegetable and other organic remains, on the other. So great must be the amount of carbonic acid annually decomposed by vegetation, that it is doubtful if the atmosphere contains enough carbonic acid to suffice (without assistance) for 50 years' growth of regetation at the present rate. This can be readily shown by a simple calculation. Let us take a very moderate estimate of the rate of growth of vegetation on the land surface of the earth, viz. 1 ton of dry wood or hay \&c. per acre per annum, this being only one-half of Liebig's estimate for ordinary meadow, forest, and agricultural land, as stated in a previous article; and let us leave the vegetation that grows in the sea out of account altogether. Now 1 ton of dry wood may be regarded as containing roughly 0.4 ton carbon, and to obtain 0.4 ton of carbon 1.456 tons of carbonic acid would have to be decomposed. 'The production of 1 ton of dry wood \&c. per acre per annum therefore requires the decomposition of 1.466 tons carbonic acid per acre per annum, which is equivalent to 939 tons per square mile, or $46,950 \times 10^{6}$ tons for the whole land surface of the earth, which may be taken in round numbers as $50,000,000$ square miles. This figure $\left(46,950 \times 10^{6}\right.$ tons $)$ is roughly the 47 th part of the total weight of atmospheric carbonic acid as given above.

A very considerable quantity of carbonic acid must also be removed from the atmosphere through the decomposition of certain rocks by water and carbonic acid, a reaction which has already been referred to. It is not very easy to 
form an approximate estimate of the quantity of carbonic acid annually removed from the atmosphere in this way, even though it is comparatively easy to form an estimate of the total quantity of carbonate of lime and other carbonates that are annually carried into the sea by rivers, the difficulty being in estimating the proportion of these carbonates that is derived from limestone and other carbonates already present in the soil and rocks subject to denudation, and the proportion that is formed through the decomposition of silicates by water and carbonic acid. However, it can be easily shown that the quantity of carbonic acid removed in this nay must be very much smaller than the quantity annually removed by the growth of vegetation. Prof. Dittmar (article on Sea Water in Encyc. Britt.) estimated that the total carbonate of lime introduced into the ocean annually by all rivers amounts to $1.34 \times 10^{9}$ tons (or the $\frac{1}{11900 \overline{0}}$ part of the carbonate of lime already present in the ocean, which he estimated at $160 \times 10^{12}$ tons). The amount of carbonic acid present in $1 \% 34 \times 10^{9}$ tons carbonate of lime is $590 \times 10^{6}$ tons, a quantity which is equal to about $-\frac{1}{80}$ of the quantity annually decomposed by vegetation as calculated above. A certain amount of carbonate of lime is no doubt also formed by the direct action of the sea on rocks containing silicates, and the free carbonic acid which takes part in this reaction may be regarded as being removed from the atmosphere since the sea and the atmosphere react on each other; but the quantity removed in this way is probably not so great as is required to form the carbonates annually carried into the sea by rivers. Also, as already remarked, it is only a portion of the carbonic acid present in the carbonates carried into the sea by rivers that can be regarded as having been derived directly from the atmosphere; and therefore we are entitled to infer that the total quantity of carbonic acid which is removed from the atmosphere through the weathering of rocks is very much less than the quantity which is decomposed through the growth of vegetation.

Of the agencies which produce or evolve carbonic acid the most important, as already stated, is the oxidation of vegetable and other organic remains. This oxidation takes place in one or other of three different ways: (1) by animal respiration, (2) by active combustion with evolution of light and heat, and (3) by eremacausis or slow decay. All of these are important as methods in which carbonic acid is produced in large quantities, and as a result of the total oxidation effected in these ways, by far the greatest proportion of vegetable and animal remains is oxidized to water and carbonic acid. Still it 
is obvious that a considerable proportion of organic remains escapes oxidation, and is preserved for a considerable time, at any rate, in the form of peat or coal. It is not easy to form an estimate of the proportion or percentage of vegetable remains that is preserved in this way; but when it is observed that about 6,000,000 acres in the United Kingdom, or nearly 8 per cent. of the total surface of the country, are covered by peat-bogs, it is obvious that the proportion must be of considerable importance. No doubt the rate of growth of vegetation in or on peat-bogs may be much less than the average rate for the whole country, and the proportion of the earth-surface, taken as a whole, which is covered by peat-bogs may be very much less than 8 per cent, ; but still it is quite possible that the amount of vegetable remains which escapes oxidation in this and in other ways may be as much as 1 per cent. of the total quantity of such remains, and probably it is at least 0.1 per cent. That is to say, there is more carbonic acid annually removed from the atmosphere by the growth of vegetation than is returned to it by the oxidation of vegetable and animal remains, the difference being probably at least $0 \cdot 1$ per cent. of the amount removed, and possibly as much as 1 per cent. or even more.

Of the other agencies which add carbonic acid to the atmosphere, the most important is probably voleanic action, or the heating of certain rocks under such conditions as to cause the evolution of carbonic acid; but still we have very little quantitative information regarding it. Boussingault considered that the volcano Cotopaxi evolved annually more carbonic acid than a whole city like Paris (which he calculated to evolve about 3,000,000 cubic metres of carbonic acid daily); and Lecoq ealculated that the mineral springs of Auvergne gave off annually $7000 \times 10^{6}$ cubic metres of carbonic acid gas, an amount rather less than $\frac{1}{10}$ of the volume produced by the annual combustion of the coal employed throughout the whole of Europe. Bischof estimated that the quantity of carbonic acid evolved in the Brohl Thal in the Eifel district of Rhenish Prussia amounted to 5,000,000 enbic feet, or 300 tons of gas per day. These are not perhaps very large quantities in themselves; but still there are many other voleanoes and volcanic regions in the world, and the total quantity of carbonic acid evolved from subterranean sources may be very large indeed. It is also known from the Report of the 'Challenger' Expedition that carbonic acid is evolved in some places at the bottom of the sea in very considerable quantities. Further, it is even possible that carbonic acid may be evolved from the ground in regions which are 
not usually regarded as being volcanic. It is well known that "ground air," that is, air lying close to the ground or enclosed within the upper layers of the soil, is usually richer in carbonic acid than the atmosphere in general. This higher percentage of carbonic acid in ground air is probably for the most part due to eremacausis or oxidation of organic matter within the soil ; but possibly it may not be all due to this cause, some of it may come from a deeper source. The carbonic acid that occurs so frequently in wells and pit-workings is not likely to be all produced by eremacausis in the upper layers of the soil, it is more likely to have a deeper source even though the source should not be of a volcanic nature.

There are still one or two other ways deserving of notice in which carbonic acid is produced and added to the atmospheric supply. The process of fermentation (natural and artificial) is one of these, and possibly it is of some quantitative importance; but still it may be regarded as a phase of eremacausis, or at least as a stage in the oxidation of certain substances, and therefore it hardly needs to be discussed separately. The combustion of ordi ary coal should also be mentioned, as coal is now mined and consumed on a very large scale, the amount now raised being about $800,000,000$ tons per annum. Taking the average amount of carbon in coal as 80 per cent., the burning of the above quantity of coal will cause the addition of about $1700 \times 10^{6}$ tons carbonic acid to the atmosphere annually. This amount is large enough to have an important bearing on the question as to whether the percentage of carbonic acid in the atmosphere is increasing at present or not; but still it is obvious that the whole period during which coal has been mined on a large scale is not verv great (from a geological standpoint); and we may quite well leave the raising and burning of coal out of consideration for the present as a noteworthy factor in the history of the atmosphere. It is therefore evident that we must look upon the carbonic acid of telluric or subterranean origin as being sufficient not only to make good the loss of atmospheric carbonic acid which is caused by the weathering of rocks, but also to make good the difference between the amount that is decomposed by the growth of vegetation and the amount that is restored to the atmosphere by the oxidation of vegetable and other organic remains. It is somewhat unfortunate that there is so little information regarding the amount of telluric carbonic acid annually evolved, but there is no difficulty in understanding that it may be or could be very large when we consider the amount of limestone and other carbonates existing in the earth, and the way in which they 
may be affected by volcanic action and caused to give up their carbonic acid. Dr. Sterry Hunt calculated that there was probably enough limestone on the earth to yield a quantity of carbonic acid equal to 200 times the volume of our present atmosphere. This quantity would be 700,000 times greater than the amount of carbonic acid at present existing in the atmosphere. It would be about $35,000,000$ times greater than the amount annually decomposed by vegetation as calculated above, and of course would be very many times greater than the difference between the amount annually decomposed by vegetation and the amount annually restored by the oxidation of organic remains. It is therefore quite clear that there are ample stores to draw upon, and a simple calculation will show that quite a limited area of country, when subjected to volcanic action, may yield a large quantity of carbonic acid.

Ordinary limestone has the specific gravity $\mathbf{2 \cdot 6}$, and therefore weighs $162 \mathrm{lbs}$. per cubic foot. It contains, if pure, 44 per cent. by weight of carbonic acid. A cubic mile of limestone therefore contains $4686 \times 10^{6}$ tons carbonic acid, a quantity which is roughly equal to $\frac{1}{10}$ of the amount that we have calculated is annually removed from the atmosphere by the growth of regetation, and 470 cubic miles of limestone contain an amount of carbonic acid equal to the total carbonic acid of the atmosphere, viz. $2 \cdot 2 \times 10^{12}$ tons. Now the average aggregate thickness of limestone and other carbonates all over the earth must be about 1.64 miles in order to contain the quantity of carbonic acid estimated by Dr. Sterry Hunt; and therefore, on the average, a surface area of $286^{\circ}$ square miles contains beneath it in the form of limestone and other carbonates as much carbonic acid as there is in the whole of the atmosphere. A region 100,000 square miles in extent will contain, on the average, ahout 350 times as much as the above quantity; and if subjected to volcanic action, we may expect that a large proportion of this carbonic acid will be evolved in the free condition. There is therefore no difficulty in understanding that there is enough carbonic acid of volcanic or telluric origin to maintain the balance or equilibrium between the amount of carbonic acid removed from the atmosphere and the amount restored to it by the various agencies already referred to. Further, it is obvious from considerations regarding the erratic or intermittent character of voleanic action generally, and also from considerations regarding variations in the composition and distribution of rocks subjected to volcanic action, that there will most probably be great variations in the amount of telluric 
carbonic acid annually evolved. If, then, there has been on the average during recent geological epochs just enough car-bonic acid of telluric origin to maintain the balance referred to above, there must have been times when much more was evolved than was required to make good the balance, and there would also be times when there was not enough evolved. Also, from considerations regarding the length of time that volcanic activity prevails or continues in any particular district, we are entitled to infer that a period, during which more telluric carbonic acid than is required for the balance is added to the atmosphere, may last for a long time-leng enough to cause a very substantial increase in the amount of carbonic acid present in the atmosphere. Further, it is possible that periods during which there is a deficiency may also last long enough to cause a serious diminution in the amount of atmospheric carbonic acid. It is thus evident that in this way very considerable variations may have taken place in the percentage of atmospheric carbonic acid during recent geological epochs; and it is quite possible that these variations may account for the climatic changes of the occurrence of which there is an abundant and striking body of evidence, and the causes of which have caused much discussion among geologists and astronomers.

As far back as 1845 or so it was pointed out by Ebelmen (as quoted by Dr. Sterry Hunt) that the greater weight of an atmosphere charged with carbonic acid would increase the temperature due to solar radiation at the earth's surface, and greatly modify atmospheric phenomena. Later on, Tyndall by his researches on radiation showed that certain gases have a very considerable heat-absorbing power; so that a small quantity of one or more of such gases present in the atmosphere might have a very considerable effect on climatic conditions. He even suggested that questions relating to the climate of different geological epochs might find their solution in the presence in the atmosphere of moderate quantities of a gas like earbonic acid.

More recently the subject has been investigated by E. Lechner of Vienna and S. Arrhenius of Stockholm. Lechner announced as the result of his investigations (Phil. Mag. ser. 5, vol. ji, 1881, p. 76) that carbonic acid rather than aqueous vapour is the constituent of the atmosphere which absorbs the sun's radiation; and he was able by his method of working to calculate the percentage of carbonic acid in the atmosphere, finding it 3.27 parts in 10,000 parts

Phil. Mag. S. 6. Vol. 9. No. 49. Jan. 1905. 
by volume, which is not far from the results obtained by chemical analysis.

Prof. Arrhenius has made an elaborate investigation of the subject by a special method, the results of which he gave in a paper published in the Philosophical Magazine for April 1896 , p. 297. From conclusions drawn from the data obtained by means of his experiments, he calculated the extent, to which the carbonic acid in the atmosphere would have to vary in order to bring about the temperature of the Tertiary and the Ice Ages respectively. He found that the temperature in the Arctic regions would rise about $8^{\circ}$ or $9^{\circ} \mathrm{C}$. if the carbonic acid were increased to 2.5 or 3 times its present value; and that in order to get the temperature of the Ice Age between the 40th and 50th parallels of latitude the earbonic acid in the air shonld sink to $0 \cdot 62-5$ of its present value (lowering the temparature by $4^{\circ}$ or $5^{\circ} \mathrm{C}$.).

Assuming that these results are reliable, the question arises as to whether it is possible or probable that the amount of carbonic acid in the atmosphere may have varied to the above extent; that is, whether it may at one period have been two or three times as much as at present, and at another period only about half of the present quantity.

If we suppose that the amount of carbonic acid annually restored to the atmosphere by the oxidation in various ways of organic remains amounts to 99.9 per cent. of the amount annually removed by the growth of vegetation and the weathering of rocks, it is evident that 0.1 per cent. of the amount would have to be added from subterraneous sources to maintain the balance; or, following the estimate above given regarding the growth of vegetation, there would be annually required $46.9 \times 10^{6}$ tons of carbonic acid of telluric origin. Now if we suppose this to be increased through any cause by 50 per cent. of itself, or $23 \cdot 4 \times 10^{6}$ tons, there would be a net addition of $23.4 \times 10^{6}$ tons per annum to the carbonic acid of the atmosphere; and if we suppose this addition or extra quantity to be continued steadily for many years, in 141,000 years the total carbonic acid of the atmosphere would be $5.5 \times 10^{12}$ tons, or $2 \frac{1}{2}$ times its present amount, and in 188,000 years it would be $6.6 \times 10^{12}$ tons, or 3 times its present amount. Similarly, if the amount of subterranean carbonic acid should fall off by the above quantity, causing a deficiency of $23 \cdot 4 \times 10^{6}$ tons per annum, and if this deficiency should continue for a long term of years, then in 47,000 years the amount of atmospheric carbonic acid would be reduced to $1.1 \times 10^{12}$ tons, or one-half of its present value.

The above figures are probably well within the limits 
imposed by the conditions of the problem (so far as these are known); that is to say, they probably do not err by being put too low, and indeed variations in the percentage of atmospheric carbonic acid to the extent indicated may have taken place in a much shorter time. For, as we have observed already, it is quite possible that the amount of carbonic acid annually restored to the atmosphere by the oxidation of organic remains in various ways may not be more, and may even be less, than $99 \cdot 0$ per cent. of the amount annually removed by the growth of vegetation and the weathering of rocks; in which case we would infer that the normal or average amount of carbonic acid of telluric origin annually added to the atmosphere is not less than 1 per cent. of the amount annually removed by vegetation \&c. Now if we suppose, as before, that the average annual amount of telluric carbonic acid is increased by one-half of itself, and that the extra quantity continues to be evolved steadily for a long time, then in 19,000 years the percentage of atmospheric carbonic acid would be increased to 3 times its present value. On the other hand, if the annual yield of telluric carbonic acid were dimiuished, and remained diminished, by one-half of its normal quantity, then the total amount of atmospheric carbonic acid would be reduced by one-half in 4700 years. Further, since it is quite possible that in periods of great volcanic activity the amount of carbonic acid evolved may be twice or even several times greater than the average or normal amount evolved, and also since it is possible that the amount evolved in very quiescent times may be much less than half the average amount, it is evident that very great changes in the amount of atmospheric carbonic acid may be brought about in considerably shorter periods than 19,000 or 4700 years.

We admit, of course, that in making calculations of this kind, some allowance might have to be made for the effect of an increase or diminution in the quantity of atmospheric carbonic acid on the luxuriance of vegetation, and the activity of other agencies which tend to remove carbonic acid from the atmosphere. It is highly probable that in the event of a large increase in the percentage of atmospheric carbonic acid, there would be an increase in the luxuriance of vegetation on the earth taken as a whole (other conditions being assumed to be as farourable as they are at present), on account of the (hypothetical) increase in temperature itself, and possibly also on account of the greater quantity of carbonic acid readily available for respiration by the leaves of vegetables. The latter is a point of considerable interest and deserves investigation. O. Wollny, who has done a $\mathrm{H} 2$ 
great amount of work in connexion with the question of local variations in the percentage of carbonic acid and allied subjects, once observed (as quoted by Prof. Letts in his work on the Carbonic Anhydride of the Atmosphere) that the "crown air" of a tall pine-tree in a plantation in the Karsten forest showed a very low percentage of carbonic acid, so low that he was not willing to accept the result; and he was of opinion that some of the carbonic acid had combined with the lead of the long tube used in the experiment, the sides of the tube having become moist. Whether this experiment should have any positive value or not, it is quite credible that on a very calm bright day the percentage of carbonic acid in the crown-air of a tree in full foliage may become much reduced by the process of respiration, and therefore the growth of the tree may be less rapid than it would be if the carbonic acid were kept up to or near its normal percentage by the circulation of the air, or otherwise. At the same time, the limits imposed on the luxuriance of vegetation in those parts of the world where it: is poor seem not to have much direct reference to the amount of carbonic acid in the atmosphere, but rather to the conditions regarding temperature, sunlight, rainfall or watersupply of some kind, and fertility of the soil. It is quite possible, however, that in regions where vegetation is very luxuriant, a certain amount of restriction is imposed by the limited quantity of atmospheric carbonic acid, especially if the weather should frequently be very calm. In the forests of the Amazons and other luxuriant forests, where the struggle for life on the part of vegatation is to a great extent a struggle for light, the amount of growth is largely conditioned by the amount of foliage that can reach the sunlight; and if the percentage of carbonic acid in the air at the tops of the trees should be much reduced in calm weather by the respiration of the leaves, it is very probable that the growth of the trees will be thereby to some extent affected.

However, it is highly probable that considerations of this kind do not after all affect the main question before us very seriously; for we have to do not so much with the total amount of vegetable growth per annum or the total amount of carbonic acid annually decomposed and otherwise removed from the atmosphere, but rather with the difference between the amount annually removed by vegetation and otherwise and the amount annually restored by eremacausis and other modes of oxidation. Now it is quite reasonable to suppose that if the luxuriance of vegetation were to be very greatly increased, the amount of carbonic acid arising from the 
oxidation of vegetable remains would be very greatly increased also, and that to an extent probably not much less than the ratio of the increase in the luxuriance of vegetation itself. The difference between the amount of carbonic acid annually decomposed by vegetation and the amount annually restored by eremacausis \&c. would no doubt be greater in such a case than it is at present; but it would not necessarily be enormously greater, and indeed it is not at all likely that it would go beyond the limits that a large increase in the supply of telluric carbonic acid (but still an increase ouly to the extent limited by the general conditions of the problem and the probabilities of the case) would be quite able to overtake.

We may thus consider that a sufficiently clear case has been made out for the variability of the amount of atmospheric carbonic acid within very wide limits, limits wide enough to make the theory that the great elimatic changes of geological history are due to variations in the amount of atmospheric carbonic acid quite a practicable, if not also a highly probable one. An interesting point that now suggests itself is whether the theory can be tested by an appeal to known geological facts; that is to say, whether there is evidence to the effect that there was great and unusual volcanic activity during or just before warm geological epochs, and a marked decrease in volcanic activity during cold or glacial epochs. In this connexion it is at once recalled that there was grent volcanic activity in Scotland during the Tertiary epoch or part of it; but still it would not do for us to lay much stress on the evidence of a high degree of volcanic activity in one locality only. In order to make this inquiry of any practical use, it would be necessary for us to have some knowledge of the general conditions as regards volcanic activity over the whole world during each epoch; the reason for this being that carbonic acid evolved in any particular region is quickly diffused through the whole atmosphere of the earth. The percentage of carbonic acid in the atmosphere is practically the same in all latitudes and longitudes; and probably this uniformity has always held good no matter what the exact percentage for the time being may have been. For the same reason also the theory of the course of climatic change that is based on variations in the percentage of atmospheric carbonic acid is general or universal in character ; that is, if climatic changes are brought about in this way at all, they must take place in all parts of the world and in both hemispheres alike, no matter where the seat of special voleanic activity (in the case of an increase in the amount of carbonic acid) may be. This feature 
of the theory is probably a distinct advantage to it when compared with other theories of climatic change; but still the theory need not be regarded as antagonistic to other theories, especially to those which have reference to changes in local conditions. There can be no doubt that variable local conditions, such as the height of the land above sea-level, the distance from the sea, and the direction of prevailing winds and ocean currents, have a very great influence on the climate of any particular locality. However, it is fairly well recognized that variations in local conditions like the above cannot be regarded as at all sufficient to account for the facts observed in connexion with the climatic changes of geological history, and a more generally operating cause must be sought for, such as we have in the variability of the carbonic acid of the atmosphere. Though I do not venture to make any definite statement about any observed connexion between volcanic activity and geological climate, I hope that geologists will state their views on the subject; and if it should be considered that there is not enough evidence to draw a definite conclusion, I hope that by and bye a sufficient amount of evidence will be obtained. In any case, as already remarked, the large amount of coal deposited in the earth is a strong argument in favour of the variability of the amount of atmospheric carbonic acid; and as it is usually considered that the periods in which large quantities of coal were deposited were warm periods, it is obvious that this also to some extent supports the view that there is a connexion between the amount of atmospheric carbonic acid and the general temperature of the atmosphere and surface of the earth.

VIII. Investigation of the Variations of Magnetic Hysteresis with Frequency. By Thomas R. Lyle, M.A., Professor of Natural Philosophy in the University of Melbourne*.

[Plate II.]

T $\mathrm{N}$ the following paper are given some results obtained by my wave-tracer, of which a description has been published in the 'Philosophical Magazine' for November 1903.

The work described, which is of a preliminary nature, was in great part performed more than a year ago, but a severe illness has prevented me until now both from preparing it for publication and from continuing as intended the same

* Communicated by the Physical Society : read Norember 11, 1904. 